Office for Education should be set up for all time, and be oriented toward the future, toward a socially improving future. Particular educational systems in any country are not suggested. Rather, the International Office should act as a clearing-house for educational ideas, an information centre for the educators and for the educational bureaux and ministries that need guidance and specific assistance in the improving of their work. In the specialized sciences and arts there have long been useful international unions. In their limited fields such organizations have shown how relatively simple it is for the people of all nations to co-operate. What has been done in the sciences can certainly be done in the general educational field. The great usefulness of the International Labour Office during the past two decades shows how important, for international understanding, an organization of this sort can be. That the establishment of an International Office of Education appeals to Americans of all sorts has been indicated by the rapid support received from scores of important organizations - from church, labour, industry and education-and from numerous members of the National Congress. It is hoped that the American Government will join with the other free governments of the world, in an official recognition of the essential part of education in the planning for a better and more peaceful world.

\section{Visual Aids in the Schoolroom}

THE remarkably comprehensive and suggestive paper recently read at the Royal Society of Arts by Mr. R. W. Moore, headmaster of Harrow, calls for special comment. The progressive teacher, he said, is alive to the uses of the epidiascope, and films have established themselves as an important subsidiary in schools. In the past, visual factors have been neglected, no doubt. Yet, he said, we must ask ourselves whether worse dangers than those of neglect are not involved in the uncritical multiplication of visual aids now prevalent in some quarters. Illustration is confused with explanation. Excess of detail, leading to distraction and irrelevance, abounds. True, the development of new processes promises a great enrichment for teacher and pupil; but our chief need is that of a psychology of education which will take account of these visual adjuncts and order them. The subjects which most need visual aids, said Mr. Moore, are science, history and geography. Of the three, he proceeded, science is the best case, because observation has long since been recognized as basic in the scientific tradition, and also scientific men have a professional bias towards, and a mechanical dexterity in, the manipulation of visual aids. History is the most difficult to accommodate to such aids. Geography stands between. It is the study of man in his natural environment. As a subject, it has only recently emancipated itself from the verbalism of the academic tradition. It should have its roots in observation and begin with local investigation. But how are we to extend the process towards a knowledge of world geography? How is the child in a poor London school to observe India and South America ? Films are here intensely valuable, but the material available is sadly thin. The present needs are : (1) that research and experiment be made inside the teaching profession towards ascertaining what visual aids are appropriate to particular subjects and purposes, and (2) that there should be thorough co-operation between teachers and manufacturers before and during production.

\section{A Natural Elastic Polyester}

Some of the newest and most fascinating developments in applied science lie in the field of high polymers - and yet the story of high polymers, since they form the principal physico-chemical basis: of life, is one of the oldest and most fundamental in the world. Most natural chain-molecules still cannot be synthesized by man; but he can build many others that are not found in Nature. Among the latter were thought to be the polyesters, first synthesized by Carothers and Arvin in 1929. It is reported now by A. R. Kemp and H. Peters (India Rubber World, 110,639 ; 1944) that what seems to be very likely a polyester constitutes the highly elastic skin that fits tightly round the seeds of Smilax rotundifolia Linn. The ripe berries usually contain three seeds about $\frac{1}{2} \mathrm{~cm}$. in diameter, each enclosed in a membrane about $0.003 \mathrm{~cm}$. thick. On removal, the membrane is found to be stretchable by $300-400$ per cent and to give then a typical $\mathrm{X}$-ray fibre photograph with a probable fibre period of about $22 \frac{1}{2} \mathrm{~A}$. This finding, taken in conjunction with chemical analyses carried out on the skins both before and after hydrolysis with alcoholic caustic potash, indicates that the main component is a polyester formed by the repeated condensation of a unit having 17 or 18 carbon atoms in the chain with two hydroxyl side groups, the suggested empirical formula of the monomer being $\mathrm{C}_{18} \mathrm{H}_{36} \mathrm{O}_{5}$. The conclusions are for the present tentative, but they are by no means unconvincing, and the results of further investigation-very much worth while-will be awaited with interest.

\section{Earthquake in Japan}

ONE of the most violent earthquakes of recent years was recorded by the seismographs at Kew, West Bromwich, New York and Bombay, and probably throughout the world, on December 7. At West Bromwich it was recorded at $4 \mathrm{~h} .48 \mathrm{~m}$. 38s. G.M.T., and the waves were so violent that the recording mechanism was upset. At Fordham, New York, the Rev. J. J. Lynch believes from a preliminary investigation of his records that two shocks were recorded, at 12.49 and 12.53 a.m. (local time). The Japanese News Agency stated that the Island of Honshu was affected, and that it was believed that the epicentre was in the Sea of Nshu. The Tokaido district was affected and also Shizuoka, Hamamatsu, Nagano and Nagoya, the third largest city of Japan. There was some damage to property and a seismic sea-wave affected Shizuoka. It appears unlikely that further details will be obtainable from Japan until the end of the War; but this was undoubtedly a very great earthquake, and when the records are examined closely the epicentre will be found more precisely.

\section{The Phosphorus Cycle in Nature}

For his presidential address to the Geological Section of the Congress of the South Eastern Union of Scientific Societies, held on October 14, Dr. K. P. Oakley took as his subject "Man and the Migrations of Phosphorus". For some time after the earth's formation, the phosphorus cycle in the sea was simple, the phosphate ions being built up into the earliest forms of organic life and released again at their death, the only loss occurring through the precipitation of phosphate ions accumulated at the lower levels, with the formation of sedimentary rock phosphate beds. Following the emergence of life from the sea and the 